\title{
The Relationship between Morphological Awareness and Vocabulary Size of EFL Learners
}

\author{
Omid Tabatabaei \\ Department of English, Najafabad Branch, Islamic Azad University, Najafabad, Iran \\ E-mail: tabatabaeiomid@yahoo.com \\ Masumeh Yakhabi \\ Department of English, Najafabad Branch, Islamic Azad University, Najafabad, Iran
}

Received: May 16, 2011

doi:10.5539/elt.v4n4p262

\author{
Accepted: June 3, 2011 \\ Published: December 1, 2011 \\ URL: http://dx.doi.org/10.5539/elt.v4n4p262
}

\begin{abstract}
The aim of this study is to investigate the relationship between morphological awareness and vocabulary knowledge of Iranian high school students. Nation's Vocabulary Level Test (VLT) was used to test students' knowledge of words drawn from the 2000, 3000 and 5000 most frequent occurring word families. Two morphological awareness tasks (a morpheme identification task and a morphological structure test) were also used to assess students' morphological awareness. The VLT results reveal that the students performed better at the 2000 level than the two higher frequency levels. There existed a significant relationship between the learners' performance on the vocabulary level test and the morphological awareness tasks. These findings implicate the importance of facilitating the students' morphological awareness in English vocabulary learning for EFL learners in Iran.
\end{abstract}

Keywords: Morphological awareness, Vocabulary knowledge, Morpheme identification, Vocabulary, Frequency

\section{Introduction}

Vocabulary is part and parcel of every language. Vocabulary items are sets of words which form the basis for producing and understanding sentences (Miller, 1991). Therefore, "without some knowledge of that vocabulary, neither language production nor language comprehension would be possible" (Angelin, Miller \& Wakefield, 1993, p. 2).

Words are the primary carriers of meaning, and it is widely recognized that there is a strong relationship between the individual's vocabulary size and his/her general language proficiency (Vermeer, 2001; Zimmerman, 2005). Methods for learning vocabulary, then, are an important part of language learning. Learners and teachers can adopt various strategies for teaching and learning vocabulary. Vocabulary learning strategy is the process, by which vocabulary is obtained, stored, retrieved, and used (Schmitt \& McCarty, 1997).

One of the strategies of word instruction is using Word-Part Clues/Morphology. As stated by Carlisle (2004), morpheme is the name for meaningful word parts that readers can identify and put together to determine the meaning of an unfamiliar word. Knowledge of morphemes and morphology, or word structure, plays a valuable role in word learning from context, because readers can use such knowledge to examine unfamiliar words and figure out their meanings. Morin (2003) proposed the strategy of using morphological knowledge to infer word meanings, and with it, the need to develop morphological awareness in the L2 would become more realized. She characterizes morphological awareness as the ability to reflect on and manipulate morphemes and word formation rules in a language.

Pica (1988, as cited in Morin, 2003) argued: "morpheme analysis can provide important insights into the sequences, processes, and input relevant to second language acquisition" (p.107). Kuo and Anderson (2006) suggest that a learner who understands how words are formed, by combining prefixes, suffixes, and roots, tends to have larger vocabulary repertoire and better reading comprehension. Anglin (1993) identifies five different morphological word types in English. The five types are root words (e.g., short, closet), inflected words (e.g., smoking, reports), derived words (e.g., shortish, treelet), literal compounds (e.g., sunburn, birthday), and opaque, idiomatic compounds or lexical idioms, which are then called simply 'idioms' (e.g., mouse tail, "a plant of the crowfoot family"; pink lady, "a cocktail"). 
In the present study, four of the morphological word types (root words, inflected words, derived words and literal compounds) were used to investigate the two types of morphological awareness: The Morpheme Identification Awareness that is defined as the ability to distinguish different meanings across homophones and Morphological Structure Awareness that is defined as the ability of learners to make use of linguistic knowledge to derive new meaning (Chang, Wagner, Muse \& Chow, 2005). In fact, in this study, the Morpheme Identification task examines the participants' knowledge of root words and use of morphemes to guess meaning, whereas the Morphological Structure task assesses the ability to create literal compounds, inflected, and derived words.

Of interest here is whether the knowledge required to complete these Morpheme Identification and Morphological Structure Awareness tasks relate to L2 vocabulary knowledge. Chang et al., (2005) believe this is important because it demonstrates that there are two different aspects of morphological awareness and that both of these might be important in fostering vocabulary acquisition.

Nunes, Bryant, and Bindman (2006) reported that the English L1 children took several years to learn to use the -ed ending systematically to denote the past of regular verbs: even at the age of 10 years many children still made mistakes with this morphologically based rule. The authors concluded that awareness of morphology influences children's knowledge of when to use or not to use the morpheme -ed.

Although only a few studies (Morin, 2003; Chang et al., 2005; and Schiff \& Calif, 2007) have examined the role of morphological awareness in L2 vocabulary development, the findings suggest that different aspects of morphological awareness may be useful for vocabulary building. Prince (2007) reports a study done by Lesaux ( in press) which indicates that a learner understands how words are formed by combining prefixes, suffixes, and roots to have larger vocabularies and better reading comprehension.

In order to investigate the role of morphological awareness in developing vocabulary for L2 learners, Morin (2003) studied Spanish classes to examine the acquisition of derivational morphology- the use of suffixes that can change the part of speech and cause variations in meaning- by native English-speaking learners of Spanish. In this study, the main questions were: 1) do beginning L2 learners who focus on Spanish derivational morphology learn more vocabulary than learners who do not, 2) can they apply morphological knowledge receptively and productively, and 3) does their success depend on their L2 proficiency level. The results indicated that the strategy for building vocabulary by consistently focusing on Spanish derivational morphology may yield immediate benefits in the area of production at least among one experimental group, the second-semester learners who were introduced to Spanish morphology. There is also a suggestion that for second-semester learners, there may be benefits or effects of such knowledge of derivational morphology with respect to their receptive morphological knowledge. In addition, the second-semester experimental group demonstrated a significantly greater knowledge of productive Spanish derivational morphology than any of the other groups studied. In her conclusion, Morin (2003) emphasized that the results of her study could not make specific claims to all learners generally. However, it does indicate a positive trend in the effectiveness of morphological knowledge as a tool for building vocabulary knowledge.

Bertram, Laine and Virkkala (2000) examined the role that morphology plays in vocabulary acquisition in L1 Finnish. Systematically, they investigated the role that affix frequency and productivity might play in the development of the children's knowledge of word. The results showed that the Finnish elementary school children benefit significantly from utilizing morphology in determining word meaning. In contrast to the research done on morphological awareness in the L1, there have been only a few studies that have focused on the morphological awareness in the L2.

Very few studies have involved training for morphological awareness, and most of them have examined the question of whether the development of morphological awareness would be beneficial to reading. In particular, Nunes et al., (2006) evidenced a positive impact of morphological training on reading. However, this impact was not specific, since it could not be differentiated from possible effects of phonological training, because the authors used a standard reading score as well as a score that specifically assessed the use of morphological rules in reading (as measured by the reading of derived words or pseudo words). Finally, the impact of morphology training was both stronger and more specific on the spelling tests than on the reading tests.

Investigating instructional approaches to the use of morpheme or root word families in teaching vocabulary for ESL learners show that the learners can develop their vocabulary better when vocabulary is taught by morphological analyses rather than through more traditional class instruction methods ( Long \& Rule, 2004 ), but these findings are not clear about EFL learners and ask for deeper investigation. This paper builds on this body of research by examining the relationship between the English vocabulary size of EFL mathematics high school students in Iran and their morphological awareness. The study to be presented here attempts to evaluate and possibly extend findings from the previous studies to the context of EFL learning in Iran. 


\section{Statement of the Problem}

Some researchers (e.g., Morin, 2003; Chang, et al., 2005; and Schiff \& Calif, 2007) have focused considerable attention on the value of teaching roots, prefixes, and suffixes for purpose of vocabulary development. The most regular strategies in Iran are using dictionaries, finding the equivalent translation, synonyms and antonyms, repeating, and memorizing words. If the learners do not practice for a long time they will forget every thing. Hence, the learners need a more effective method for learning new words. Although, morphological awareness can play an important role in EFL learners' comprehension, Iranian learners mostly try to find the meaning of unknown words through the context (Taghipour, 1999). Moreover, few studies (compared with those conducted on phonological awareness) have investigated the morphological aspects of language learning. Longitudinal and correlational studies, however, have suggested that morphological awareness- defined as the ability to consciously manipulate morphemic units- may also be an important aspect of learning language (Carlisle, 1995). Hence, it seems crucial to conduct more studies examining the importance of morphological awareness in vocabulary learning.

\section{Objectives of the Study}

This study mainly aims to investigate the relationship between English morphological awareness and vocabulary knowledge in the context of English as a foreign language (EFL). It also considers theoretical and practical aspects of morphological awareness measurements and how they relate to the learner's vocabulary knowledge and to improve vocabulary teaching methods with a focus on possible implications that this relationship might have for incorporating morphological awareness as a part of vocabulary instruction in the L2 classroom.

\section{Research Questions}

An attempt has been made in this study to seek appropriate answers to the following questions:

1. What is the vocabulary size of the Iranian high school students in the study?

2. What level of English morphological awareness do these learners possess?

3. Is there a connection between students' morphological awareness and vocabulary size?

\section{Research Hypothesis}

There is no relationship between students' morphological awareness and vocabulary size.

\section{Significance of the Study}

The results obtained from this study can be advantageous to the following groups of people:

Text book designers can apply some exercise relating to the morphological awareness in the text books, therefore learners can practice this vocabulary learning strategy more and consequently can have a better performance on their tests and have more educated guesses when encounter new texts.

Publishers can publish dictionaries of roots, suffixes and prefixes to enable the students have an easy access to the different possible parts of words and increase their morphological knowledge and vocabulary domain.

Teachers can provide some extra activities in the classroom such as unseen reading texts which are full of new words containing suffixes and prefixes in order to improve the students' morphological awareness.

\section{Methodology}

\subsection{Participants}

The participants in this study were male senior high school students whose major was mathematics. The study was limited to male students in order to prevent the effect of gender on the findings of the study. Nelson (2001) low intermediate proficiency test was administered to select 50 homogeneous students for the experiment. It seemed that they had enough proficiency and ability to answer Vocabulary Level Test (VLT), because they had learned English as a foreign language for about 6 years and English is also considered as a requirement for university entrance, thus it is an important part of the curriculum at schools. The mathematics students were chosen because in comparison with the literature and natural science majors, their courses are more inferential and analytic. Moreover, based on the interview done by the researcher, they were more eager to participate in English classes and they liked English more than the students of the other two majors.

\subsection{Instruments}

\subsubsection{Nelson Test}

This test was used to identify the learners' proficiency level. It consisted of 50 questions (Fowler \& Norman, 2001). Its reliability was calculated through KR-21 formula in the pilot study $(0.82)$. The validity was also confirmed by 
three competent experts in the field who had extensive experience in test construction.

\subsubsection{VLT (Nation, 2001)}

It was used to measure the students' receptive vocabulary size. This test was chosen because it is a commonly used test with easy administration and scoring. Since the participants were pre-university students, the receptive vocabulary levels test was used to test the participants' knowledge of vocabulary items from the 2000,3000 , and 5000 most frequently occurring words. These are seen as words that all learners need to know to be able to read basic texts and that should be concentrated on in the class (Nation, 2001). Each level has ten items containing six words and three meanings and the participants must choose the right word to go with each meaning.

\subsubsection{Morphological Awareness Test}

The learners' morphological knowledge was tested by the Morphological Awareness Test presented in Chang et al (2005). This test consisted of two parts: a Morpheme Identification Awareness Test and a Morphological Structural Awareness Test.

\subsubsection{Morpheme Identification Awareness}

Chang, et al. (2005) define awareness of Morpheme Identification as the ability to distinguish different meanings across homophones, for example by understanding that flower in flowerpot is represented by a plant with petals as opposed to a sack of white powder (flour). The authors believe that this aspect of morphological awareness might help language learners to distinguish among meanings of syllables with identical sounds, facilitating language analysis and vocabulary growth. The Morpheme Identification test consisted of one example and five test items. All the items have two pictures and the subjects were asked to look at the pictures and then answer the questions by choosing the correct picture containing the meaning of the target word. The purpose of the first test was to verify the participants' ability to distinguish homophones.

\subsubsection{Morphological Structure Awareness}

The other type of morphological knowledge measured in this study is the awareness of morphological structure. This morphological structure requires learners to make use of linguistic knowledge to derive new meaning. This test consisted of three scenarios illustrating objects that are regularly encountered in daily life, as well as some which are rarer. As was the case with the previous test, the items were adapted from Chang et al (2005). The participants were asked to come up with words to describe objects or concepts presented by each scenario. Fifteen of the scenarios required responses involving morpheme compounding, whereas the remaining six items involved syntactic manipulation.

\subsection{Procedures}

At first Nelson low intermediate proficiency test was administered to 85 senior high school students whose major was mathematics. Then 50 students whose scores fell between one standard deviation above and one standard deviation below the mean were selected. After choosing the appropriate population, the main tests were administered. The tests consisted of three parts. Part 1 was Nation's Level Test (VLT-90 items). Part two was the Morpheme Identification Test (5 items) and part 3, the Morphological Structural Awareness Test (20 items). The tests were administered over two days to minimize fatigue. The first day of testing consisted of the VLT, and the second day of testing included the morphological awareness test. The participants received instruction for each part only on the day the particular test was run. Then the obtained results were submitted to statistical analysis.

\section{Data Analysis}

\subsection{Results of vocabulary level tests}

Initially, in order to know that the data obtained for answering the research questions were interpretable, it was necessary to obtain a reliability score for the VLT used in this study. Test reliability for the VLT was assessed using KR-21formula. The reliability of the total test, containing 90 questions, was 0.94 . In detail, each level of the VLT $(2000,3000$ and 5000) also indicated high reliability. At the 2000 level, the alpha was .85, whereas at the 3000 and 5000 levels, the alphas were .84 and .88 respectively. This indicated that the scores obtained were highly reliable.

The performance on these three sections of the VLT is presented in Figure1 (see list of Figures). The vertical axis indicates the number of correct answers out of 30 questions for each test. In this figure, results of vocabulary level test 2000, 3000 and 5000 are presented. It can be concluded that by decreasing the frequency of words, the correct score averages of these tests would reduce. In addition, standard deviations of these tests would decrease too which is also understandable based on height of vertical lines. Descriptive statistics of this figure are presented in Table 1. (See list of tables) 
As Table 1 shows, the means of vocabulary level tests, in 2000, 3000, and 5000 are 18, 13.56, and 11.02 respectively. It also reveals the minimum scores for these three levels which are 7 in 2000 words, 4 in 3000 words, and 3 in 5000 words, while the maximum scores are 28, 22, and 19. The students know approximately 1200 words.

The standard deviations of these tests are 6.03, 4.27, and 3.47. Decreasing standard deviation means that the difference between the most knowledgeable and the least knowledgeable students for each test has decreased which was logically predictable. In other words, when students face a hard test, they will answer the questions based on their guesses; therefore, the result would seem similar to each other with no difference between weak and strong students, it means that the test discrimination decreases. The comparison of the means in the three vocabulary levels (2000, 3000, and 5000) shows a sharp decrease between 2000 and 3000 but not between 3000 and 5000 .

The results of these tests must be reliable because the researcher needs them to evaluate the relationship between morphology and vocabulary. Grouping method was used to find the relation between 2000, 3000 and 5000 tests. It has been found that these tests have a significant difference with an acceptable accuracy. It means that these three vocabulary levels are really different from each other and assess different vocabulary levels of students.

One-way ANOVA (Analysis of variances) procedure was applied to the obtained experimental data as presented in Table 2 (see list of tables). The tests were classified in different groups named A, B and C based on the values of Critical Value of F and Least Significant Difference (LSD).

It was found that there is a logical relationship between these tests. So the results of these tests can be used to study morphological awareness.

\subsection{Results of morphological awareness test}

In order to be sure that the data obtained for answering the research questions was reliable, it was necessary to obtain a reliability score for the morpheme identification test and morphological structure test used in this study. Test reliability for both of the above tests was assessed using Cronbach alpha (Brown, 2001). The reliability of the morpheme identification test, containing 5 questions, was .71 and the reliability of the morphological structure test, containing 20 questions, was 80 .

The results of these tests are presented in Fig 2 (see list of Figures). The vertical axis indicates the number of correct answers for each test. In morpheme identification test the correct answers are out of 5, while in morphological structures, they are out of 20. The averages of correct answers are 4.14 and 13.94 respectively.

This figure also indicates that as the number of questions decreases, data distribution would cluster around standard deviation, because in morpheme identification test there is a more limited range of scores than in morphological structure test. Because in morpheme identification test the minimum and maximum is between 0 and 5 , but in morphological structure, it is between 0 and 20. The details of this figure are presented in Table 3 (see list of tables).

As Table 3 shows, the means of morpheme identification test is 4.14 and it is 13.93 for morphological structure. The minimum scores for these two tests are 3 and 6 respectively while their maximum scores are 5 and 20 . The standard deviation of morpheme identification test is 0.80 and it is 3.15 for morphological structure.

A t-test was run on the obtained experimental data as presented in Table 4 (see list of tables). The tests (morphological identification and morphological structure) were classified in different groups named A and B based on the values of Critical Value of $t$ and Least Significant Difference (LSD). Grouping method shows that these two tests are different and assess two different aspects of morphological awareness which are morpheme identification and morphological structure.

\subsection{The relationship between VLT and morphological awareness test}

In this section, the relationship between individual VLT and the average of these tests were compared with that of morpheme identification tests and morphological structural awareness.

First, the relationship between the averages of 2000, 3000 and 5000 tests with morphological tests were studied. The details of this comparison are presented in Table 5 (see list of tables).

Pearson Correlation coefficient was run on the obtained experimental data as presented in Table 6 (see list of tables). Based on the obtained statistical parameters, it can be concluded that both morpheme identification and morphological structure are related to the average of VLT and vice versa. Pearson Correlation parameters of VLT average to morpheme identification and morphological structure are 0.87 and .85 respectively, meaning that the average of VLT is more related to morpheme identification than morphological structure.

This analysis can be repeated to find the correlation of each 2000, 3000 and 5000 vocabulary level tests to morphological tests. Pearson Correlation coefficient was run on the obtained experimental data as presented in Table 
7.

Based on the obtained statistical parameters, it can be concluded that both of morpheme identification and morphological structure are related to all vocabulary level tests with different parameters. Pearson Correlation parameters of 2000, 3000 and 5000 tests to morpheme identification are $0.92,0.79$ and 0.65 respectively. It means that morpheme identification is more related to VLT with easier tests. In addition, similar to the average of VLT, all of 2000, 3000 and 5000 tests are more related to morpheme identification than morphological structure.

\section{Discussion}

\subsection{English vocabulary size}

The first research question concerned the size of the English vocabulary of Iranian senior high school students in the study, as reflected in their performance on the VLT. The vocabulary size score was assumed to highlight the students' vocabulary proficiency after studying English for almost 6 years. The results revealed that the students performed better in doing the vocabulary test at the 2000 level than at the 3000 and 5000 levels of the VLT. This indicates a better result compared with the previous study by Taghipour (1999), who found that the average first year Iranian university students only master about 1040 English words.

This conclusion is based on two considerations:

1. Simply referring to Zimmerman (2005), the scores on the VLT test can be used to provide a rough estimate of the vocabulary size. For example, if a participant can answer correctly 9 items out of 18 items in 1000 level, it can be assumed that s/he knows roughly 500 out of the 1000 words families from that level. Thus, in the present study, on average the students obtained the score $60 \%$. It can be calculated then that they know approximately 1200 words.

2. The participants in the current study are assumed to learn English in a shorter term compared to the participants in the previous study. The first year Iranian university students in the former study are in general assumed to have already learnt English for seven years, while the pre-university students in the latter study are generally assumed to have studied English for six years.

Beside the two considerations, it is also interesting to evaluate the vocabulary size for senior high school students (4000-5000 words) confirmed by Taghipour (1999). Nagy and Anderson (1984) found that there was a lack of agreement among the researchers about an absolute vocabulary size for any given age or development level. Similarly, Zechmeister, D'anna, Hall, Paus and Smith (1993) stated that there are many apparent logical inconsistencies in vocabulary-size as mentioned in the literature. In addition, most of the thresholds proposed are intended for English L1 users, not ESL or EFL learners.

Nagy and Anderson (1984) presented a discussion about getting the real picture of the students' vocabulary size through the number of words they have to deal with in school reading. Information on the amount and type of reading done by the students in and out of school is required to reanalyze the vocabulary size by grade level. Nagy and Anderson (1984) considered the pages of texts the students read at school per day, as well as the speed of the words they read per minute to estimate the vocabulary size that the students should have. Applying this calculation into the Iranian context, the threshold confirmed by the previous study could be unrealistic because of some limitations in Iranian senior high schools. First, English is taught for four and/or six hours meeting. During that time, all four skills - listening, reading, writing and speaking - are taught to the students, not only reading. Second, most of the students get the reading sources only at school, not at their home environment. Therefore, on average the English passage the students read each day will be very limited with a low word-reading rate as well.

To see the relation between these three tests- 2000, 3000, and 5000- grouping test method and also t-test were applied to the obtained experimental data. Finally, the Critical Value of $t$ and Least Significant Difference (LSD) revealed that there is a logical relationship between these tests.

\subsection{Morphological awareness}

The second question addressed in the study concerned the level of morphological awareness possessed by the participants in the study. For the Morpheme Identification test, the results show that the students could perform well in choosing one target picture as the one that best corresponded to the meaning of the morpheme intended. However, the results also show the appearance of a ceiling effect, which is consistent with the previous study by Chang et al. (2005). The students answered the questions very well and more than $40 \%$ of the participants obtained the maximal score, $100 \%$. This ceiling effect is assumed to cause the test items to be less reliable (the analysis of the test reliability resulted an alpha coefficient of .71). The limited number of the ceiling effect may be also because the items in the Morpheme Identification tasks were modified in this study, different from the study conducted by Chang et al. (2005). 
Unlike the Morpheme Identification measure, the Morphological Structure results were of satisfactorily reliable (the analysis of the test reliability confirmed it with an alpha coefficient of .80). On the Morphological Structure test, the mean was 13.94 and the standard deviation was 3.15.

An analysis of the Morphological Structure items shows that the students performed better in compounding words than using their syntax knowledge to create new words. The underlying reason seems to be the different kinds of the mental processes that participants have to go through. This means that in the first part (compounding words), all the learner has to do is to follow the presented model and substitute the new words in their appropriate places exactly like the model. However, in the second part, the learner has to go deeper into his syntactic knowledge and finds the appropriate morpheme for making new words based on the scenarios presented.

Other patterns were found in a further analysis of each item in the Morphological Structure test. In forming new compounds by stringing together other words, the participants show better performance when the target words were in the same grammatical category such as noun + noun, as in milk glass and tea cup. However, none of the students answered correctly when they were asked to create donut tree after they were given apple tree as a compound word from apples and tree. This could be linked to the different features of the two target words, one is plural (apples and donuts), another is singular (tree). The participants could not apply their syntactic knowledge about the importance of deleting $-\mathrm{s}$ ending from donuts to form the compound donut tree. Another underlying reason seems to be that plural 's' addition (when making countable nouns) in comparison with plural 's' deletion (when compounding with another word) has much more frequency in English. Based on Schmidt's noticing hypothesis, the higher the frequency of occurrence of a feature, the higher would be the probability that it is noticed, becomes more salient and consequently acquired. In Iran, EFL learners are taught to add plural 's' to countable nouns at the first stages of language learning and then hear, see and use it very frequently, while 's' deletion when its accompanying word is combined with another noun is the rule which is taught quite later with less emphasis, and the learners hear or see it in written form with much less frequency.

Similarly, the participants could not perform well in compounds formed with a preposition. There were only 11 students who answered over-ground train correctly after being given example in the same category, under-ground train to indicate train that runs over the ground. Most of the students did not exclude the verb runs from their answer, thus most of the answers were runs over ground train. The most probable reason seems to be that these students believe runs as the word which carries one of the key semantic features (motion/movement) of the noun that if it is not added to noun through the compound adjective accompanying it, the meaning of train may be deficient.

In the second part of the morphological structure test, using inflectional morphology to understand novel words, some trends emerge in the participants' performance. The students show better performance in applying the -ed and -ing suffixes as the marker for past and present participle with $81 \%, 60 \%$ and $66 \%$ correct answer respectively. However, they seem to have problem in using the -ing suffix for making frogging from frogs as an association to the example of raindrops and raining.

Moreover, the students obtained a low mean average in applying the -es suffix as the marker for plurality. There are only $10 \%$ of the students answered correctly for huxes, even though they performed better in applying $-\mathrm{s}$ suffix for wugs with $56 \%$ correct answer. This fact can be explained based on the markedness theory. Celce- Murcia and Hawkins (1985, p. 66) sum up markedness theory as follows:

"It distinguishes members of a pair of related forms or structures by assuming that the marked member of a pair contains at least one more feature than the unmarked one. In addition, the unmarked (or neutral) member of the pair is the one with a wider range of distribution than the marked one. For example, in the case of the English indefinite articles ( $a \& a n$ ), an is the more complex or marked form (it has an additional sound) and $a$ is the unmarked form with the wider distribution."

Eckman (1981) showed that marked items in a language will be more difficult to acquire than unmarked ones, and that degrees of markedness will correspond to degrees of difficulty. Rutherford (1982) used markedness theory to explain why there seems to be a certain order of acquisition of morphemes in English: marked structures are acquired later than unmarked structures. In this study, the (es) morpheme is the marked, more complex member with one more feature $(e)$ and less distribution that is more difficult to acquire in comparison with the unmarked member $(s)$ that has wider range of distribution and is less complex to acquire.

In a previous study, Lyytinen and Lyytinen (2004) suggest that early identification of grammatical markers is important for L1 children because the markers may persist and influence the children's following language development. Noun inflections were acquired early; followed by verb inflections; and finally verb and adjective inflections at the following age. The results of the present study do not support this result. The participants here performed better in understanding verb inflections than noun inflections. Thus, an alternative explanation suggested 
by Adams and Huggins (1985, as cited in Wysocki \& Jenkins, 1987) can be taken into consideration. The ability to use contextual information to identify words depended not on age or development level, but mainly on the familiarity with the target words. This may also explain the result of the present study.

The Morpheme Identification test may have tapped semantic association knowledge by its use of pictures. However, it is assumed that pictures were needed to represent two homophones since the tests were given in written form, not in an oral one. In Morpheme Identification, the pictures made it easier for learners to guess the target words. On the other hand, in Morphological Structure Test learners could apply their analysis of the example given to get the target words. This point is consistent with that of the previous study by Chang et al., (2005). In their study, they argued that through the Morphological Structure Test, the children were asked to combine morphemes in new ways. Noticing similarities across words, the children could build on their morphological knowledge, and it was more efficient for them to learn new words. With knowledge of morphemes, it was found easier to understand new vocabulary by generalizing the morphemes to new contexts.

\subsection{The relationship between morphological awareness and English vocabulary knowledge}

The third research question concerned the possible relationship between performance on the VLT vocabulary on the VLT vocabulary measure and the morphological awareness test.

Consistent with the previous study by Chang et al., (2005), the results for the group as a whole reveal that there is a significant relationship between these two variables, vocabulary size and morphological awareness. However, because this is a correlational study, the causal relationship among them cannot be predicted. In addition, when the two morphological awareness measures were correlated there was a correlation coefficient, indicating that they were measuring different kinds of knowledge, at least to some degree.

Based on the obtained statistical parameters, it can be concluded that both morpheme identification and morphological structure are related to the average of VLT and vice versa. Pearson Correlation parameters of VLT average to morpheme identification and morphological structure are 0.87 and 0.85 respectively, which means the average of VLT is more related to morpheme identification than morphological structure. This analysis was repeated to find the correlation of each 2000, 3000 and 5000 vocabulary level tests to morphological tests.

Pearson Correlation test was run on the obtained experimental data. Based on the obtained statistical parameters, it can be concluded that both of morpheme identification and morphological structure are related to all VLT with different parameters. Pearson Correlation parameters of 2000, 3000 and 5000 tests to morpheme identification are $0.92,0.79$ and 0.65 respectively meaning that morpheme identification is more related to VLT with easier tests. In addition, similar to average of VLT, all of 2000, 3000 and 5000 tests are more related to morpheme identification than morphological structure. This finding can be explained based on the concept of 'level of processing'. According to this concept, stimuli can be analyzed to varying depths. In the shallow level, processing corresponds to activation of nodes in the sensory analyzer. In the medium level, stimuli recognition (identification) occurs in the semantic analyzer where we not only sense the stimuli but also perceive it. In the next level that includes syntactic analyzer; deeper processing that involves understanding or interpreting of the stimuli occurs. This third level deals with deeper and more abstract mental processes than sensation and perception. It seems that in this study, the majority of the participants succeeded at activating nodes in the medium level at semantic analyzer which is accountable for correct word identification. However, not all these participants could go deeper to the syntactic analyzer and apply the appropriate morphological rule for making a new word.

When the learners noticed similarities across words, they started building on their morphological knowledge. Also, as they acquired new vocabulary, they can analyze vocabulary items into sub lexical components such as morphemes more easily. Further research is needed on this issue.

In addition, concerning the strategies the participants used in learning English vocabulary, Anglin (1993) believes that none of the students wrote about learning English vocabulary by inferring the meaning from morphological knowledge. Thus, the results of this study may suggest to the students a new method that they can use in their vocabulary learning and they can also include morphological analyses as one of their stages in vocabulary learning.

\section{Conclusion}

Findings of the study showed that the participants had their best performance in level 2000, and as the word frequency decreased the correct score averages of these tests and their standard deviations reduced. Moreover, the analysis of the Morphological Structure items indicated that the students performed better on compounding words than using their syntax knowledge to create new words. Also, in forming new compounds by stringing together other words, the participants show better performance when the target words were in the same grammatical category such as noun + noun. Based on the obtained statistical parameter, it can be concluded that both morpheme identification 
and morphological structure are related to the average of VLT and vice versa, but the average of VLT is more related to morpheme identification than morphological structure.

\section{Pedagogical Implications}

Based on the findings of this study it is suggested that teachers should introduce aspects of morphological knowledge to the students learning vocabulary. Initially, teachers should give explicit instruction and then gradually the learners can apply their morphological awareness automatically when faced with new vocabulary that has the possibility of morphological analysis. Moreover, the significant correlation of morphological awareness to vocabulary size may suggest the need to apply this strategy for English vocabulary learning of the students. Finally the students themselves confirmed their interest in using this method in their learning. Therefore, the concept of using morphological knowledge as a vocabulary-building tool is necessary to be included in the curriculum.

\section{References}

Anglin, J. M., Miller, G. A., \& Wakefield, P. C. (1993). Vocabulary development: A morphological analysis. Monographs of the Society for Research in Child Development, Vocabulary Development: A Morphological Analysis, 58(10), 1-186

Bertram, R., Laine, M., \& Virkkala, M. M. (2000). The role of derivational morphology in vocabulary acquisition: get with a little help from my morpheme friends. Scandinavian Journal of Psychology, 42, 287-296. http://dx.doi.org/10.1111/1467-9450.00201

Carlisle, J. F. (1995). An exploratory study of morphological errors in children's written stories. Reading and Writing: An Interdisciplinary Journal, 8, 61-72. http://dx.doi.org/10.1007/BF00423925

Carlisle, J. F. (2004). Morphological processes influencing literacy learning. In C. A. Stone, E. R. Silliman, B. J. Ehren, \& K. Apel (Eds.), Handbook on language and literacy: Development and disorders. New York: Guilford. pp. 318-339

Celce- Murcia, M., \& Hawkins, B. (1985). Contrastive analysis, error analysis, and inter language analysis. In H. Douglas Brown (Ed.) Principles of language teaching and learning. Sanfrancisco State University. pp. 215-231

Chang, C. M., Wagner, R. K., Muse, A., W. Y. B., \& Chow, H. S. (2005). The role of morphological awareness in children's vocabulary acquisition in England. Applied Psycholinguistics, 26, 415-435

Eckman, F. R. (1981). On the naturalness of interlanguage phonological rules. Language Learning, 31, 195-216. http://dx.doi.org/10.1111/j.1467-1770.1981.tb01379.x

Fowler, W. S., \&Norman, C. (2001). Nelson English language tests. Middlesex: Thomas Nelson.

Kuo, L. J., \& Anderson, R. C. (2006). Morphological awareness and learning to read: A cross-language perspective. Educational Psychologist, 41(3), 161-180. http://dx.doi.org/10.1207/s15326985ep4103_3

Lyytinen, P., \& Lyytinen, H. (2004). Growth and predictive relations of vocabulary and inflectional morphology in children with and without familial risk for dyslexia. Applied Psycholinguistics, 25, 397-411. http://dx.doi.org/10.1017/S0142716404001183

Long, d., \& Rule, A. C. (2004). Learning vocabulary through morpheme word family object boxes. Journal of Authentic Learning, 1, 40-50

Miller, G. A. (1991). The science of words. New York: Scientific American Library.

Morin, R. (2003). Derivational morphological analysis as a strategy for vocabulary acquisition in Spanish. The Modern Language Journal, 87, 200-221

Nagy, W. E., \& Anderson, R. C. (1984). How many words are there in printed school English? Reading Research Quarterly, 19(3), 304-330

Nation, I. S. P. (2001). Learning vocabulary in another language. Cambridge; New York: Cambridge University Press.

Nunes, T., Bryant P., \& Bindman, M. (2006). The effects of learning to spell on children's awareness of morphology. Reading and Writing, 19, 767-787. http://dx.doi.org/10.1007/s11145-006-9025-y

Prince, r. E. C. (2007). Morphological analysis: New light on a vital reading skill (Electronic Version). [Online] Available: http://www.uknow.gse.harvard.eedu/teaching/TC102-407.html (May 2007)

Rutherford, W. (1982). Markedness in second language acquisition. Language Learning, 32, 85-108

Schiff, \& Calif, S. (2007). Role of phonological and morphological; awareness in L2 oral word reading. Language 
learning, 57, 271-298

Schmitt, N., \& McCarty, M. (1997). Vocabulary description, acquisition and pedagogy. Cambridge: Cambridge University Press.

Taghipour, M. (1999). Vocabulary learning strategies of Iranian undergraduate students. Applied Linguistics, 19 (2), 255-271. 19, 737-765

Vermeer, A. (2001). Breadth and depth of vocabulary in relation to L1/L Acquisition and frequency of input. Applied Psycholinguistics, 22(2), 217-234

Wysocki, K., \& Jenkins, J. R. (1987). Deriving word meanings through morphological generalization. Reading Research Quarterly, 22(1), 66-81. http://dx.doi.org/10.2307/747721

Zechmeister, E. B., D Anna, C. A., Hall, J. W., Paus, C. H., \& Smith, J. A. (1993). Metacognitive and other knowledge about the mental lexicon: do we know how many words we know? Applied Linguistics, 14(2), 188-206

Zimmerman, K. (2005). Newly placed versus continuing students: comparing vocabulary size. TESL Reporter, 38(1), $52-60$

Table 1. Descriptive statistics of vocabulary level test 2000,3000, and 5000

\begin{tabular}{|c|c|c|c|}
\hline & 2000 & 3000 & 5000 \\
\hline Mean & 18 & 13.56 & 11.02 \\
\hline Min & 7 & 4 & 3 \\
\hline Max & 28 & 22 & 19 \\
\hline SD & 6.0339 & 4.2721 & 3.4728 \\
\hline
\end{tabular}

Table 2. Analysis of experimental data

\begin{tabular}{|l|c|}
\hline Alpha & 0.05 \\
\hline Error Degrees of Freedom & 147 \\
\hline Errör Mean Square & 22.24014 \\
\hline Critical Value of F & 1.97623 \\
\hline Least Significant Difference & 1.864 \\
\hline
\end{tabular}

\begin{tabular}{|c|c|c|c|}
\hline t Grouping & Mean & $\mathrm{N}$ & test \\
\hline $\mathrm{A}$ & 18.0000 & 50 & test 2000 \\
\hline $\mathrm{B}$ & 13.5600 & 50 & test3000 \\
\hline $\mathrm{C}$ & 11.0200 & 50 & test5000 \\
\hline
\end{tabular}

Table 3. Descriptive statistics of morpheme identification and morphological structure

\begin{tabular}{|c|c|c|}
\hline & Identification & Structure \\
\hline Mean & 4.14 & 13.94 \\
\hline Min & 3 & 6 \\
\hline Max & 5 & 20 \\
\hline SD & 0.8083 & 3.1584 \\
\hline
\end{tabular}


Table 4. Analysis of experimental data with t-test

\begin{tabular}{|l|c|}
\hline Alpha & 0.05 \\
\hline Error Degrees of Freedom & 98 \\
\hline Error Mean Square & 5.314694 \\
\hline Critical Value of t & 1.98447 \\
\hline Least Significant Difference & 0.915 \\
\hline
\end{tabular}

\begin{tabular}{|c|c|c|c|}
\hline t Grouping & Mean & $\mathrm{N}$ & $\mathrm{t}$ \\
\hline $\mathrm{A}$ & 13.9400 & 50 & $\begin{array}{c}\text { Morphological } \\
\text { structure }\end{array}$ \\
\hline $\mathrm{B}$ & 4.1400 & 50 & $\begin{array}{c}\text { Morpheme } \\
\text { identification }\end{array}$ \\
\hline
\end{tabular}

Table 5. Descriptive statistics of vocabulary level tests averages with morphological awareness test

\begin{tabular}{|l|c|c|c|c|c|c|}
\hline Variable & $\mathrm{N}$ & Mean & STD Dev & Sum & Minimum & Maximum \\
\hline average & 50 & 14.19333 & 4.281 & 709.6667 & 5 & 23 \\
\hline identification & 50 & 4.14 & 0.80837 & 207 & 3 & 5 \\
\hline structure & 50 & 13.94 & 3.15847 & 697 & 6 & 20 \\
\hline
\end{tabular}

Table 6. Analysis of Pearson Correlation coefficient for average, morpheme identification and morphological structure

\begin{tabular}{|c|c|c|c|}
\hline & average & identification & structure \\
\hline average & 1.00000 & $\begin{array}{c}0.87660 \\
<.0001\end{array}$ & $\begin{array}{c}0.85968 \\
<.0001\end{array}$ \\
\hline identification & 0.87660 & 1.00000 & 0.83464 \\
& $<.0001$ & & $<.0001$ \\
\hline structure & 0.85968 & 0.83464 & 1.00000 \\
& $<.0001$ & $<.0001$ & \\
\hline
\end{tabular}

Table 7. Analysis of Pearson Correlation coefficient for 2000, 3000, 5000 morpheme identification and morphological structure

\begin{tabular}{|c|c|c|c|c|c|}
\hline & $\mathrm{t} 2$ & $\mathrm{t} 3$ & $\mathrm{t} 5$ & identification & structure \\
\hline $\mathrm{t} 2$ & 1.00000 & 0.89144 & 0.68173 & 0.92466 & 0.89951 \\
& & $<.0001$ & $<.0001$ & $<.0001$ & $<.0001$ \\
\hline $\mathrm{t} 3$ & 0.89144 & 1.00000 & 0.79841 & 0.79824 & 0.78447 \\
& $<.0001$ & & $<.0001$ & $<.0001$ & $<.0001$ \\
\hline $\mathrm{t} 5$ & 0.68173 & 0.79841 & 1.00000 & 0.65323 & 0.65130 \\
& $<.0001$ & $<.0001$ & & $<.0001$ & $<.0001$ \\
\hline identification & 0.92466 & 0.79824 & 0.65323 & 1.00000 & 0.83464 \\
& $<.0001$ & $<.0001$ & $<.0001$ & & $<.0001$ \\
\hline structure & 0.89951 & 0.78447 & 0.65130 & 0.83464 & 1.00000 \\
& $<.0001$ & $<.0001$ & $<.0001$ & $<.0001$ & \\
\hline
\end{tabular}




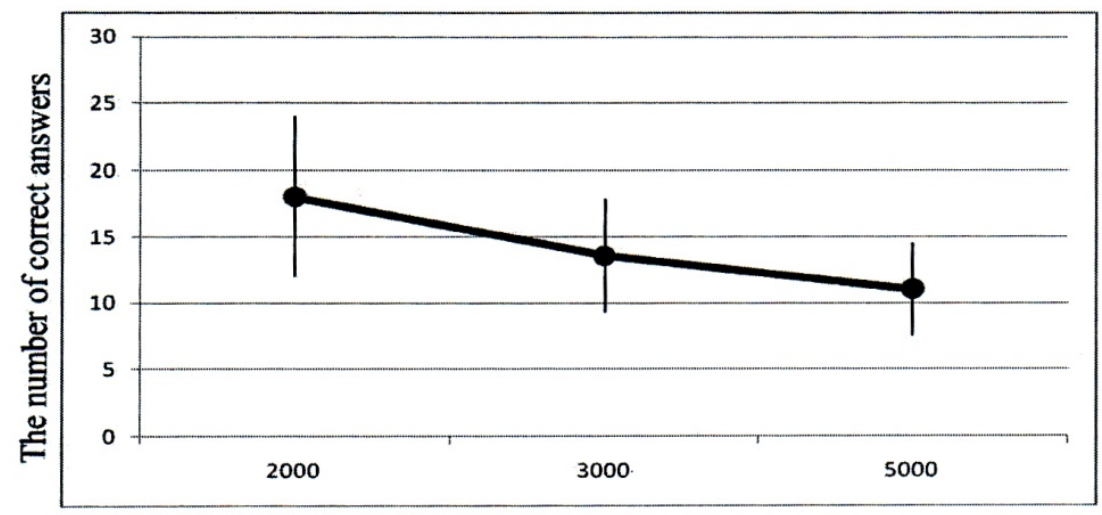

Three different vocabulary levels

Figure 1. Vocabulary levels

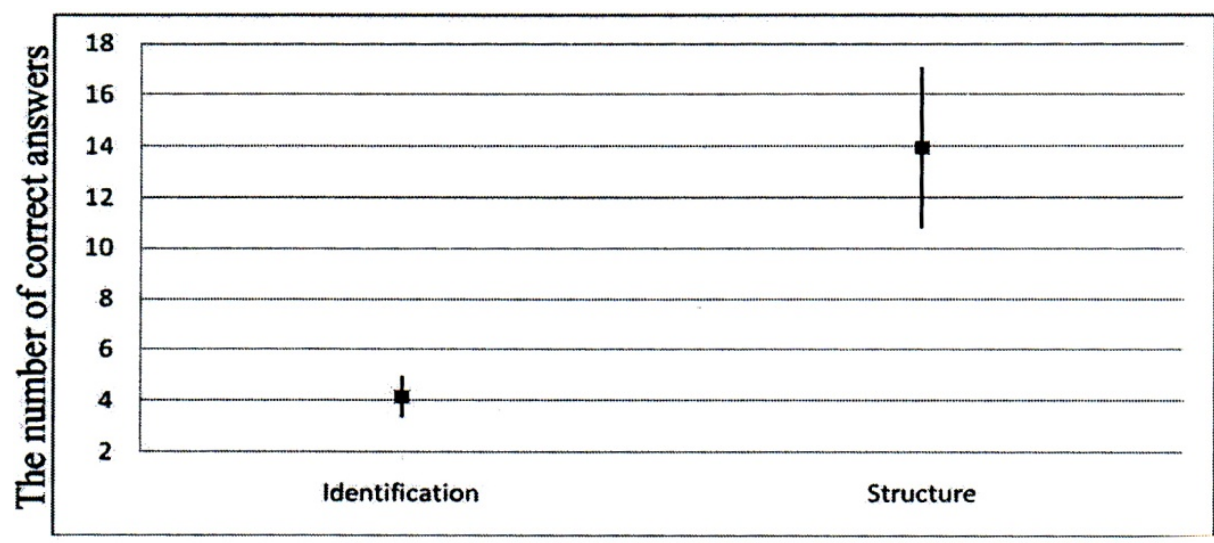

Figure 2. Identification and structures 